\title{
Early diagnosis of signet ring cell carcinoma of the stomach: role of the Genta stain
}

\author{
Hala M T El-Zimaity, Kemal Itani, David Y Graham
}

\begin{abstract}
Signet ring cell carcinoma is a poorly differentiated adenocarcinoma in which the tumour cells invade singly or in small groups. Early stages of the disease can be missed easily when using regular haematoxylin and eosin staining. This is a report of a case in which routine screening of gastric biopsies with the Genta stain was responsible for rapid identification of signet ring carcinoma. The patient, a 29 year old woman, had a large portion of the antrum excised surgically for signet ring cell gastric carcinoma. Follow up endoscopy six years later showed no evidence of tumour. Twenty six large cup biopsies were obtained and a single focus of signet ring tumour cells infiltrating the surface mucosa in single files was seen. The diagnosis was missed on haematoxylin and eosin stain by three senior pathologists but owing to the Alcian blue component of the Genta stain the tumour cells were recognised easily. Thus, the Genta stain not only facilitates detection of Helicobacter pylori but also allows for simultaneous visualisation of gastric morphology as well as signet ring carcinoma that can be missed with conventional stains. (f Clin Pathol 1997;50:867-868)
\end{abstract}

Keywords: signet ring cell; Genta stain; gastric carcinoma; early diagnosis

The Department of Medicine, Veterans Affairs Medical Center, Baylor College of Medicine, Houston, Texas, USA

H M T El-Zimaity

D Y Graham

\section{Department of Surgery}

K Itani

Correspondence to: Dr El-Zimaity, VA Medical Center (111-D), 2002 Holcombe Blvd (Room 3A352), Houston, TX 77030, USA.

Accepted for publication 12 June 1997 the Genta stain routinely on all gastric mucosal biopsies. We report a case of signet ring cell carcinoma in which routine use of the Genta stain in screening gastric biopsies not only facilitated the identification of $H$ pylori infec- tion, but also allowed the detection of malignant cells in an unsuspected case that might otherwise have gone unnoticed.

\section{Case report}

In 1990, a 29 year old woman with a history of peptic ulcer disease presented with nausea, vomiting, and decreased appetite of a few weeks duration. Upper gastrointestinal endoscopy with biopsy showed a pyloric stricture, 4-5 $\mathrm{mm}$ in greatest diameter. Repeat biopsy revealed signet ring cell carcinoma. An antrectomy with Billroth II anastomosis was performed. The tumour was multifocal, formed an ulcer at the gastroduodenal junction, and extended to the muscle layer. Frozen sections of the surgical margins were all negative for tumour as were regional lymph nodes, the peritoneum, and the liver. Gross staging, according to Borrmann's classification and TNM staging, showed type IIb, ${ }^{8}$ and T2 N0 M0 (stage I), respectively.

The patient returned six years later and endoscopy showed a normal postoperative stomach. Twenty six large cup mucosal biopsies were obtained and a single focus of signet ring tumour cells infiltrating the surface mucosa in single files was identified, with an identical histological pattern to the original tumour. The diagnosis was missed on haematoxylin and eosin stain by two senior pathologists. As part of our routine, additional slides are always stained with the Genta stain; owing to the Alcian blue component in the Genta stain, both $H$ pylori infection and the tumour cells were recognised easily (fig 1 ).

The patient underwent gastrectomy with regional lymph node dissection. The resected stomach was opened along the lesser curvature based on the information of the known topographical site from which the positive biopsy specimen had been taken. The resected stomach showed no gross identifiable tumour. The areas around the positive biopsy site were sectioned serially at $\sim 3 \mathrm{~mm}$ intervals for histological examinations, 32 sections being prepared. Microscopic examination showed marked foveolar hyperplasia (fig 2) as is seen frequently in postgastrectomy specimens, but the tumour could not be identified in the initial microscopic sections, and 30 additional 


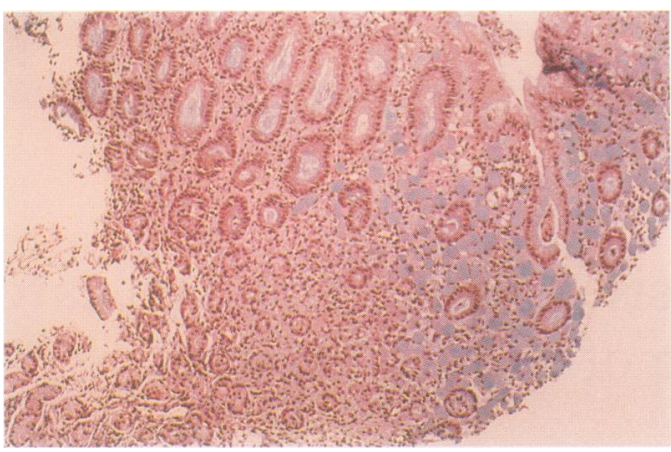

Figure 1 Signet ring cells showing a positive reaction (light blue colour) for mucin (Genta stain; original magnification $\times 10$ ).

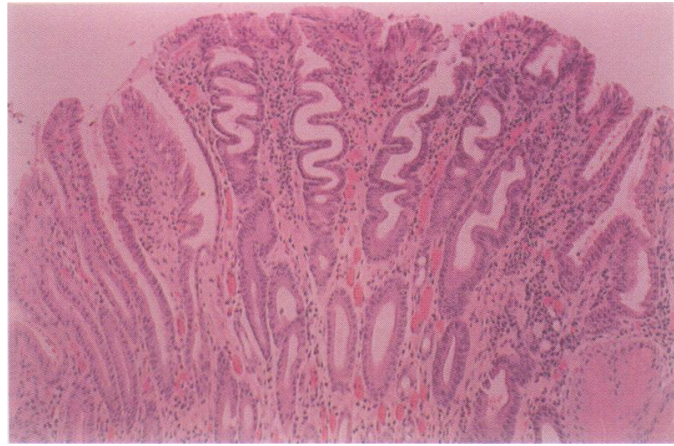

Figure 2 Signet ring cell carcinoma infiltrating the lamina propria. The background is hyperplastic foveolar epithelium typical of chemical gastropathy (haematoxylin and eosin; original magnification $\times 10$ ).

sections were cut. Histological examination in one single section showed mucosal infiltration by a population of uniform, plump, mucous containing cells with eccentrically compressed hyperchromatic nuclei (signet ring cells). The tumour was $0.5 \mathrm{~cm}$ in the greatest dimension. The main lesion was confined to the lamina propria above the muscle layer, did not involve the overlying surface epithelium, and showed no fibrous reaction. The diagnosis was missed by three senior pathologists on haematoxylin and eosin stain (fig 2). Staging according to Borrmann's macroscopic types was IIb. ${ }^{8}$

\section{Discussion}

Gastric carcinomas hidden beneath intact mucosal surface epithelium are rarely discovered. Not only is the diagnosis incidental in the early stages but, usually, it is also unexpected. ${ }^{9}$ Needless to say, a significant diagnostic delay exists in younger patients owing to the higher numbers of diffuse carcinoma ${ }^{3}$ and the low level of suspicion by both the endoscopist and the pathologist. ${ }^{41011}$ Early gastric cancer has a higher proportion of signet ring cells. ${ }^{69}$ The imperceptible IIb carcinomas are most often poorly differentiated. ${ }^{9}$ It seems reasonable to postulate that most carcinomas start as microcarcinomas of the endoscopic type IIb. Likewise, it seems reasonable to assume that if diffuse carcinoma is diagnosed in its early stages, the prognosis would be much better. ${ }^{9}$ Unfortunately, these malignant cells are missed very easily as they usually occur in non-metaplastic mucosa. ${ }^{59}$ This is exaggerated further in postgastrectomy specimens and in gastric carci- noma complicating Menetrier's disease, ${ }^{12}$ in which the hyperplastic changes of the overlying epithelium and glands allow an innocuous nest of tumour cells to be overlooked easily. Signet ring cell carcinoma is one of the few malignant tumours that is likely to be missed on microscopic examination ${ }^{9}$ because often it is misinterpreted initially as some type of benign process $^{6}$ such as an aggregate of histiocytes, xanthelasma, ${ }^{13}$ or a cohesive cluster of pyloric cells with glassy cytoplasm.

Fortunately, the periodic acid Schiff (PAS) stain and mucin stains, such as mucicarmine or Alcian blue, are helpful in highlighting signet ring cells. Mucin stains are crucial for the identification of gastric carcinoma cells in normal mucosa and in hyperplastic epithelium, where their presence may be imperceptible. In poorly differentiated carcinomas, the number of tumour cells demonstrated by mucin stains is usually much higher than that seen in haematoxylin and eosin stained sections and the routine use of special stains such as the Genta stain has an additional benefit of alerting the unwary pathologist to the presence of carcinoma. For example, a high index of suspicion would exist when an expansion of the lamina propria with blue cells is noted on low power microscopic examination (fig 1). The differentiation from histiocytes, which may be mucicarminophilic, ${ }^{14}$ can be made by cytomorphological examination of tumour cells with the PAS stain and/or the immunohistochemical cytokeratin stain.

Usually, gastric carcinoma in young patients is lethal. ${ }^{311}$ Whether the remaining focus of signet ring cell carcinoma in this patient was residual tumour or new tumour is impossible to know but the long survival of our patient is unusual. In conclusion, routine staining of gastric biopsies with the Genta stain can facilitate detection of $H$ pylori infection and signet ring cells in unsuspected cases that otherwise might be missed with conventional stains.

1 Antonioli DA, Goldman H. Changes in the location and type of gastric adenocarcinoma. Cancer 1982;50:775-81.

Munoz N, Asvall J. Time trends of intestinal and diffuse types of gastric cancer in Norway. Int 7 Cancer 1971;8:144 57.

3 Grabiec J, Owen DA. Carcinoma of the stomach in young persons. Cancer 1985;56:388-96.

4 Tamura PY, Curtiss C. Carcinoma of the stomach in the young adult. Cancer 1960;13:379-85.

5 Kim J-P, Kim S-C, Yang H-K. Prognostic significance of signet ring cell carcinoma of the stomach. Surg Oncol 1994 3:221-7.

6 Maehara Y, Sakaguchi Y, Moriguchi S, Orita H, Korenaga $\mathrm{D}, \mathrm{Kohnoe} \mathrm{S}$, et al. Signet ring cell carcinoma of the stomach. Cancer 1992;69:1645-50.

7 Genta RM, Robason GO, Graham DY. Simultaneous visualization of Helicobacter pylori and gastric morphology: a new stain. Hum Pathol 1994;25:221-6.

8 Murakami T. Pathomorphological diagnosis. Definition and gross classification of early gastric cancer. In: Ishikawa S, gross classification of early gastric cancer. In: Ishikawa S, Miyaji T, Ono T, et al, eds. Early
versity Park Press, 1972:53-5.

9 Yamashina M. A variant of early gastric carcinoma histologic and histochemical studies of early signet ring cell carcinomas discovered beneath preserved surface epithelium. Cancer 1986;58:1333-9.

10 Klein EW, Williams SF. Carcinoma of the stomach in young adults. Am $\mathcal{F}$ Gastroenterol 1962;38:69-74.

11 Tso PL, Bringaze III WL, Dauterive AH, Correa P, Cohn I. Gastric carcinoma in the young. Cancer 1987;59:1362-5.

12 Shenoy KJ, Naik R. Gastric carcinoma complicatin Menetrierw's disease-a case report. Ind $\Im$ Pathol Microbio 1994;37(suppl):S54-5.

13 Ludvikova M, Michal M, Datkova D. Gastric xanthelasma associated with diffuse signet ring carcinoma. A potential diagnostic problem. Histopathology 1994;25:581-2.

14 Kuo I, Hsueh S. Mucicarminophilic histiocytosis. Am f Surg Pathol 1984;8:419-28. 